\title{
Increased bioavailability of phenolic acids and enhanced vascular function following intake of feruloyl esterase-processed high fibre bread: a randomized, controlled, single blind, crossover human intervention trial
}

Article

Accepted Version

Creative Commons: Attribution-Noncommercial-No Derivative Works 4.0

Turner, A. L., Michaelson, L. V., Shewry, P. R., Lovegrove, A. and Spencer, J. P. E. (2021) Increased bioavailability of phenolic acids and enhanced vascular function following intake of feruloyl esterase-processed high fibre bread: a randomized, controlled, single blind, crossover human intervention trial. Clinical Nutrition, 40 (3). pp. 788-795. ISSN 0261-5614 doi: https://doi.org/10.1016/j.clnu.2020.07.026 Available at https://centaur.reading.ac.uk/93683/

It is advisable to refer to the publisher's version if you intend to cite from the work. See Guidance on citing.

To link to this article DOI: http://dx.doi.org/10.1016/j.clnu.2020.07.026

Publisher: Elsevier 
including copyright law. Copyright and IPR is retained by the creators or other copyright holders. Terms and conditions for use of this material are defined in the End User Agreement.

\section{www.reading.ac.uk/centaur}

\section{CentAUR}

Central Archive at the University of Reading

Reading's research outputs online 
Increased bioavailability of phenolic acids and enhanced vascular function following intake of feruloyl esterase-processed high fibre bread: a randomized, controlled, single blind, crossover human intervention trial.

Alice L. Turner ${ }^{\mathrm{a}}$, Louise V. Michaelson ${ }^{\mathrm{b}}$, Peter R. Shewry ${ }^{\mathrm{b}}$, Alison Lovegrove ${ }^{\mathrm{b}}$ and Jeremy P. E. Spencer $^{\mathrm{a}^{*}}$.

${ }^{a}$ Department of Food and Nutritional Sciences, School of Chemistry, Food and Pharmacy, University of Reading, Reading. UK (ALT, JPES).

${ }^{\mathrm{b}}$ Department of Plant Sciences, Rothamsted Research, Harpenden, UK (LVM, PRS, AL).

School of Agriculture, Policy and Development, University of Reading, Reading, Berks. UK (PRS).

Corresponding author: *JPE Spencer. Department of Food and Nutritional Sciences, University of Reading, Reading. UK. Tel: +44 (0) 1183788724 j.p.e.spencer@ reading.ac.uk

Short Running Head: Free FA bread and vascular function

Clinical Trial Registry: No: NCT03946293; Website: www.clinicaltrials.gov 
ABSTRACT

3

Background and Aims: Clinical trial data have indicated an association between wholegrain consumption and a reduction in surrogate markers of cardiovascular disease. Phenolics present in wholegrain bound to arabinoxylan fibre may contribute these effects, particularly when released enzymatically from the fiber prior to ingestion. The aim of the present study was therefore to determine whether the intake of high fibre bread containing higher free ferulic acid (FA) levels (enzymatically released during processing) enhances human endothelium-dependent vascular function.

Methods: A randomized, single masked, controlled, crossover, human intervention study was conducted on 19 healthy men. Individuals consumed either a high fibre flatbread with enzymatically released free FA (14.22 mg), an equivalent standard high fibre bread (2.34 $\mathrm{mg})$, or a white bread control (0.48 mg) and markers of vascular function and plasma phenolic acid concentrations were measured at baseline, 2, 5 and 7 hours post consumption.

Results: Significantly increased brachial arterial dilation was observed following consumption of the high free FA ('enzyme-treated') high fibre bread verses both a white flatbread ( $2 \mathrm{~h}: p<0.05$; $5 \mathrm{~h}$ : $p<0.01)$ and a standard high fibre flatbread (5h: $p<0.05)$. Concurrently, significant increases in plasma FA levels were observed, at $2 \mathrm{~h}(p<0.01)$ after consumption of the enzyme-treated flatbread, relative to control treatments. Blood pressure, heart rate, DVP-SI and DVP-RI were not significantly altered following intake of any of the breads $(p>0.05)$.

Conclusion: Dietary intake of bread, processed enzymatically to release FA from arabinoxylan fiber during production increases the bioavailability of FA, and induces acute endotheliumdependent vasodilation.

4 Key Words: bioavailability, ferulic acid, vascular function, high fibre bread, human intervention, feruloyl esterase. 
Abbreviations: Cardio-Vascular Disease (CVD), Flow Mediated Dilatation (FMD), Laser Doppler Imaging (LDI), Digital Pulse Wave (DVP), Blood Pressure (BP), acetylcholine (Ach), 3,5Dichloro-4-hydroxybenzoic acid (3,5DHBA)

\section{Funding:}

This work was supported financially by the Biotechnology and Biological Sciences Research Council (BBSRC), UK (BB/M002802/1) and the BBSRC Diet and Health Research Industry Club (BB/L02540X/1). Rothamsted Research receives grant-aided support from the BBSRC of the UK and the work reported here forms part of the Designing Future Wheat Institute Strategic Programme [BB/P016855/1]; Tailoring Plant Metabolism [BBS/E/C/000I0420]. 


\section{INTRODUCTION}

Clinical data suggest that the regular intake of foods/beverages rich in phenolic compounds, such as cocoa, green tea, and berries, improves human vascular function and maintains a healthy circulatory function [1-4]. However, such foods/beverages tend to be expensive, have limited availability and are not consumed by large proportions of the population. Thus, to increase the intake of phenolic compounds at the population level, in a sustainable, economically viable way, requires their delivery through foods derived from staple crops such as rice, maize and wheat. Wholegrain wheat is a rich source of phenolic acids, in particular ferulic acid (FA) [5,6], in addition to vitamins, minerals, phytosterols, unsaturated fatty acids and lignans $[7,8]$, and is consumed as both white and wholemeal breads and other cereal products. There is robust scientific evidence that diets rich in wholegrain have a beneficial effect on cardiovascular health [9-12] and current dietary guidelines emphasize the importance of wholegrain in the diet [13].

A number of components of wheat have been suggested to contribute to the cardiovascular health benefits associated with wholegrain consumption, most notably the fiber component $[6,11,14,15]$. However, phenolic compounds that are bound to arabinoxylan fibre, particularly the hydroxycinnamate FA, may also contribute, in part, to vascular health effects [16-18]. FA comprises up to $90 \%$ of the phenolic acids present in wholegrain wheat and is concentrated in the outer and aleurone layers of the grain (the bran) where it is present in three forms: as soluble free acid, soluble conjugates, and insoluble bound forms [6,19]. The latter constitute the majority of FA, and is covalently linked to arabinoxylan polysaccharides via stable ester bonds. Bound FA may also act as structural cross-links in cell walls, by oxidative dimerization [20]. Although cleavage of the ester linkage to release free FA is possible in the colon via fecal microbial xylanases and esterases, it is estimated that only about $25 \%$ of bound FA is released during this phase of digestion [21-24]. Consequently, its liberation and absorption in the gastrointestinal tract and potential to induce beneficial vascular changes in humans is limited, although slow release and absorption of phenolic acids in the gut may contribute to the long-term benefits of regular wholegrain consumption [25]. 
54 In the present study, we produced high fibre bread with high amounts of free FA, released enzymatically during dough development, in order to determine whether dietary-relevant amounts of free FA delivered in high fibre bread are capable of inducing acute beneficial effects upon endothelial function.

\section{SUBJECTS AND METHODS}

\section{Production and composition of breads}

Triticum aestivum cv Hereward was grown at Rothamsted Research (Harpenden, UK) and milled by Campden BRI (Chipping Campden, UK) using a Buhler MLU-202 mill (Urzwil, Switzerland) to give 10 fractions; Reduction 1 (R1), Reduction 2 (R2), Reduction 3 (R3), Break 1 (B1), Break 2 (B2), Break 3 (B3), Bran Flour (BF), Offal Flour (OF), Bran Off-tails (BO) and Offal Off-tails (OOT). Selected fractions were combined to produce experimental unleavened breads: white flour was prepared by combining breaks 1,2 and 3 and reductions 1,2 and 3 with an extraction rate of $72.0 \%$ of total flour. 'High fibre' flour was prepared by combining 9 fractions: breaks 1, 2 and 3, reductions 1, 2 and 3, bran flour, offal flour, and offal off tails with an extraction rate of $85 \%$ of total flour. The bran off-tails were not included in the 'high fibre' flour as their coarse texture reduced the palatability of the breads. The FA content of the milled wheat fractions is shown in Supplemental data, Table S1. Intervention breads (unleavened, flatbreads) were produced by combining flour, water, enzyme (Ultraflo $\mathrm{L}^{\circledR}$ ) and salt (Table 1) for 5 min using a Buhler mixer. Ultraflo $\mathrm{L}^{\circledR}$, a commercial $\beta$-glucanase, which also possesses xylanase and feruloyl esterase activities, was used to release FA bound to arabinoxylan. For the breads used in the intervention study this enzyme mixture was diluted in water at a ratio of 95:5 (water:Ultraflo L®, (v/v)). Dough was made using flour, water (containing the 5\% enzyme solution) and salt in the following proportions $60.5 \%$ flour; $38.7 \%$ water; $0.7 \%$ salt. The dough was left to prove for 4 hours in a temperature-controlled environment $\left(20^{\circ} \mathrm{C}\right)$, before being divided into $50 \mathrm{~g}$ portions and rolled to 13 $\mathrm{cm} \times 2 \mathrm{~mm}$ disks. The unleavened flatbreads were baked for 7 minutes at $230^{\circ} \mathrm{C}$ and left to cool. 
79

The control breads (white and high fibre) contained deactivated Ultraflo $\mathrm{L} \circledast\left(95^{\circ} \mathrm{C}\right.$ for 30 minutes, then cooled on ice).

The white intervention bread differed in appearance to the high fiber breads due to the flours used in each, although there were no observable differences between the standard and enzyme-treated high fibre breads. The optimum conditions for enzymatic release of FA from arabinoxylan during dough proving were established prior to the production of breads for intervention (Supplementary Figures $2 \mathrm{~A}$ and $2 \mathrm{~B}$ ). All breads were made at the same time and stored at $-20^{\circ} \mathrm{C}$ until use. No significant degradation of FA was observed within breads following 2 or 4 weeks of storage at $20^{\circ} \mathrm{C}(\mathrm{p}>0.05)$ (data not shown). (1)

(1)

Phenolic acids present in the original milling fractions ( $n=3$ ) (Supplementary Table S1) and in the final intervention breads $(n=3)$ (Table 1) were quantified as described by [6]. Briefly, after addition of an internal standard free phenolic acids were extracted from finely ground material in $80 \%(\mathrm{v} / \mathrm{v})$ ethanol. Bound phenolics were determined in samples after the removal of free and conjugated phenolic acids. Internal standard was added to the remaining residue and $2 \mathrm{M} \mathrm{NaOH}$ added to release the esterified phenolic acids. Following centrifugation, the supernatant was acidified with $12 \mathrm{M} \mathrm{HCl}$, mixed thoroughly, ethyl acetate added, mixed and centrifuged again. The upper phase was removed, and the ethyl acetate extraction repeated a further two times. The combined supernatants are evaporated to dryness in a Speedvac. The dry sample was then re-suspended in $2 \%$ (v/v) acetic acid, centrifuged and FA levels quantified using an Agilent 1100 HPLC equipped with a diode array detector (as described by [6], using authentic standards and an internal standard (3,5Dichloro-4-hydroxybenzoic acid). All fractions were dried prior to re-suspension in $2 \%$ (v/v) acetic acid. $50 \mu \mathrm{l}$ of each extract was separated using a Discovery RP-Amide C16 column ( 250 x4.6mm, $5 \mu \mathrm{m}$ ) maintained at $30^{\circ} \mathrm{C}$. The mobile phases consisted of a mixture of acetonitrile (solution A) and $2 \%(\mathrm{v} / \mathrm{v})$ acetic acid in water (solution $\mathrm{B}$ ) with a flow rate of $1.0 \mathrm{~mL} / \mathrm{min}$. The following 
105

106

107

108

109

110

gradient system was used (min/\% B): 0/100, 30/85, 50/50, 70/30, with 10 min post-run for column re-equilibration. The wavelength used for quantification of FA was $280 \mathrm{~nm}$ and spectral characteristics were scanned over the range $200-600 \mathrm{~nm}$. All data were analyzed using ChemStation software.

\section{Ethics}

The clinical trial was registered at clinicaltrials.gov (NCT03946293) and conducted according to the Declaration of Helsinki following Good Clinical Practice (GCP) and was approved for conduct by the University of Reading's Research Ethics Committee (ethics reference number 12/06). All volunteers signed an informed consent form before commencing the study.

\section{Intervention study population}

Healthy male volunteers ( $n=19)$ (Figure 1) were recruited from the University of Reading and surrounding areas by use of the Hugh Sinclair Unit volunteer database, poster advertisement within the university and local community via local websites. Volunteers were screened and selected according to the following inclusion criteria: 1) fasting lipids in the upper half of the normal range (triacylglycerol 0.8-3.2 mmol/l and total cholesterol 6.0-8.0 mmol/l); 2) BMI 25-32 kg/m²; 3) nonsmoker; 4) not diabetic (diagnosed or fasting glucose $<7 \mathrm{mmol} / \mathrm{l}$ ) or suffer from endocrine disorders; 5) hemoglobin and liver enzymes levels within the normal range [Alanine Transaminase (ALT): 0-55 IU/L; Alkaline Phosphatase (ALP): 38-126 U/L; Aspartate Transaminase (AST): 0-45 IU/L; Gamma Glutamyl Transferase (GGT): 12-58 IU/L]); 6) not having suffered a myocardial infarction/stroke in the past 12 months; 7) not suffering from renal or bowel disease or have a history of choleostatic liver or pancreatitis; 8) not on drug treatment for hyperlipidemia, hypertension, inflammation or hyper-coagulation; 9) not taking any fish oil, fatty acid or vitamin and mineral supplements; 10) no history of alcohol misuse; 11) not planning, or on a weight reduction regime; 12) not having taken antibiotics in the 6 months prior to the study; and 13) being able to consume the study interventions. The 19 individuals selected for the study were instructed 
not to alter their usual dietary or fluid intake, with respect to amount consumed. Volunteers were requested to refrain from the following, $24 \mathrm{~h}$ prior to, and during, the study visits: 1) consumption of polyphenol-rich foods including fruits, vegetables, wholegrain bread/pasta/rice, cocoa, coffee, tea and wine; 2) participating in vigorous exercise (> $3 \times 20 \mathrm{~min} /$ week); and 3) consuming more than $168 \mathrm{~g}$ of alcohol (any form) per week. Volunteers were further asked to fast for 12 hours before each study visit and during that period only consume low-nitrate water provided. The Baseline characteristics of the study population are presented in Table 1.

\section{Study design}

The study was a randomized, single blind, crossover, controlled intervention trial in which subjects attended the Hugh Sinclair Unit of Human Nutrition on 3 separate occasions. We considered the trial to be single blinded (researcher) as interventions differed slightly in appearance, although no information regarding the interventions could be implied from this. Visits were separated by at least 2 weeks, and treatments to subjects were allocated randomly using a restricted Williams design (as patients were recruited sequentially) by an independent researcher, who implemented the allocation sequence on the first visit. On arrival, subjects were rested in the supine position for at least 30 minutes in a quiet, air-conditioned environment $\left(22-24^{\circ} \mathrm{C}\right)$, during which time they were cannulated for venous blood collection and baseline vascular measurements were taken, including FMD of the brachial artery (primary outcome), laser Doppler imaging (LDI) with iontophoresis, and digital pulse wave (DVP), and systolic and diastolic blood pressure (Omron MX2 automatic digital upper arm blood pressure monitor). Following collection of baseline measurements, volunteers were requested to consume three $30 \mathrm{~g}$ flatbreads (white, standard high fibre, or enzymetreated high fibre) within a 5 min period and further blood was collected at 1, 2, 3, 4, 5, 6 and $7 \mathrm{~h}$ and vascular measurements were conducted at 2, 5 and $7 \mathrm{~h}$. Volunteers were provided with a lowfat, low-polyphenol lunch (consisting of 2 slices of white bread, low fat cream cheese containing $3 \%$ fat, lightly salted crisps and a low-fat vanilla yoghurt) at $3 \mathrm{~h}$ and had free access to bottled water containing low nitrate/nitrite levels) throughout the study day. Following completion of each 
experimental arm, participants followed a washout period of 14 days prior, where they were asked to follow their normal habitual diet, before switching to an alternate arm of the trial. A qualified nurse was responsible for cannulation and blood collection. All study personnel, including research nurses and research staff were blinded to the interventions. The study followed ethical standards, which were in accordance with the University of Reading Ethics Committee. No changes were made to any of the trial methods or outcomes following the commencement of the trial. Recruitment for the trial took place between Oct 2012 and February 2013, whilst the trial was conducted between January 2013 and January 2014.

\section{Flow Mediated Dilatation (FMD)}

Subjects were positioned into the supine position with the right arm rested on a custom-made arm support at a $90^{\circ}$ angle with their hand facing towards the ceiling. Electrocardiogram (ECG) pads were attached to time each image frame with respect to the cardiac cycle. A sphygmomanometric cuff was placed on the forearm and an image of the longitudinal brachial artery was obtained using a $3.5 \times 1.0 \mathrm{~cm}$ hockey-stick probe, attached to a flexible holding device with locking action to allow for accurate measurements, and ATL Ultrasound HDI5000 broadband ultrasound system. The live image was captured using image-grabbing software (MIA-llc) and collected images at 0.25 frames/second. A baseline measurement was recorded for 40 seconds using the flow. After this the main FMD measurement was started by recording the image for 60 seconds before arterial occlusion was created by inflating the cuff to $220 \mathrm{mmHg}$ causing ischemia of the arterial vessel. After 5 minutes the cuff was deflated, rapidly causing a decrease in pressure leading to reactive hyperemia to accommodate the dilated resistance levels. Image collection continued for 5 minutes post release and analysis of the arterial diameter was performed to assess the flexibility of the artery calculated as the relative diastolic diameter change from baseline compared to the peak diastolic diameter. Analysis was performed using a semi-automated computerized analysis system (Brachial Analyzer; Medical Imaging Applications-11c). In order to avoid potential inter-individual, and intra-individual variability of measurements within our experimental group, the same researcher 
conducted all FMD measurements. Additionally, care was taken to conduct brachial artery flowmediated dilatation measurements consistently, with probe placements and cuff positioning carefully recorded and replicated between and across individuals.

\section{Laser Doppler Imaging with iontophoresis (LDI)}

The assessment of peripheral microvascular function [26,27] was conducted via the administration of an endothelial-dependent vasodilator, acetylcholine ACh (1\%), and an endothelium in-dependent vasodilator, sodium nitroprusside (SNP) $(1 \%)$, to the skin, which were delivered transdermally using iontophoresis. Subjects were rested in the supine position, with their right arm supported by an armrest. Two ION 6 chambers were applied to the forearm, within $1 \mathrm{~cm}$ of each other, using double sided adhesive disks. $2.5 \mathrm{ml}$ of freshly prepared $\mathrm{ACh}(1 \% \mathrm{w} / \mathrm{v}$ in $0.5 \%(\mathrm{w} / \mathrm{v}) \mathrm{NaCl}$ solution; Sigma Aldrich, Poole, Dorset, UK) was introduced to the anodal chamber and $2.5 \mathrm{ml}$ of SNP (1\% w/v in $0.5 \%$ (w/v) NaCl solution; Sigma Aldrich, Poole, Dorset, UK) into the cathodal chamber. A coverslip was placed over each chamber to prevent any liquid from escaping. After baseline of skin perfusion was measured, an incremental electrical current was delivered simultaneously across the two chambers using the laser Doppler imager (LD12-VR) and MIC2 iontophoresis controller (Moor

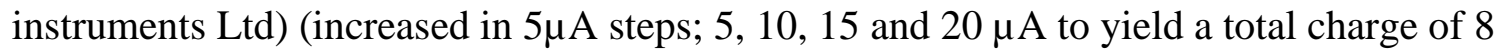
milliCoulombs within 12 minutes). A total of 20 scans were performed. An indicator of microvascular response due to ACh and SNP was calculated by the area under the flux versus time curve during the 20 scans.

\section{Digital Volume Pulse (DVP)}

The DVP stiffness index (DVP-SI) and DVP reflexion index (DVP-RI) was calculated by placing a PulseTrace PCA 2 with a photoplethysmograph transducer (MircoMedical, Kent) on the index finger of the left hand, transmitting an infrared light at 940nm. DVP was conducted as previously described [28-30]. The infrared light transmission through the finger records the systolic and diastolic waveforms of the pulse, and also records the stiffness index (DVP-SI) and reflexion index 
208 (DVP-RI). The DVP-SI (in $\mathrm{m} / \mathrm{s}$ ) is related to large arterial stiffness and is measured by dividing the 209 height of the subject by the time between the first and the second wave peaks of the DVP. It is 210 related to CVD risk factors such as blood pressure, age and waist to hip ratio. The DVP-RI is 211 related to smaller artery stiffness and is defined as the relative height of the second peak compared 212 with the first.

\section{Plasma FA analysis}

214 Blood was collected at baseline and 1, 2, 3, 4, 5,6 and 7h after ingestion and processed as described 215 in [31] and analyzed as follows. LC-MS analysis, as described by [32], with minor modifications 216 was also used to assess FA levels and other phenolic acids in human plasma samples. Measurements 217 were performed on an ABSciex 4000QTRAP MS system linked to an Agilent 1200 HPLC, column 218 oven set to $30{ }^{\circ} \mathrm{C}$, flow rate $200 \mu \mathrm{l} / \mathrm{min}$. The column eluent was introduced into the mass spectrometer 219 by a TurboIonSpray probe operating at $475^{\circ} \mathrm{C}$, with ion spray voltage set in negative mode to -4500 220 V. Both the nebulizer gas pressure (GS1) and turbo heater gas (GS2) were set to 60 psi. The curtain 221 gas flow was set to $25 \mathrm{l} / \mathrm{min}$. The MS data were collected in MRM scan mode with compound222 dependent parameters.

\section{Data handling, power calculations and statistical analysis}

224 The power calculation was based on the primary clinical outcome measure (FMD of the brachial 225 artery) in order to determine the minimum number of participants required for the study. The 226 minimal physiologically significant improvement on FMD measurable is an absolute change of 227 between 1 to $2 \%$ in FMD, considering a baseline vasodilatation of $4-6 \%$. The sample size was 228 calculated based on the variance of repeated measurement in the control group and on control data.

229 Consequently, with a standard deviation within patients of $2.3 \%$ (based on previous studies 230 performed in our group), a significance level of 0.05 and a power of $80 \%, 18$ subjects were required 231 in order to determine a significant within-subject difference between treatments of at least $2.1 \%$.

232 Two-way repeated measured ANOVA was used to analyze all data using GraphPad Prism version 4 233 (GraphPad Software Inc., San Diego, CA, US). Post hoc analysis was conducted using a Bonferroni 
234 multiple comparisons test. Significance was defined as $P<0.05$, with $P$ values represented in the 235 figures as $* P=0.01-0.05, * * P=0.001-0.01, * * * P=<0.001$, $* * * * P=<0.0001$. The incremental 236 area under the LDI flux versus time curve (IAUC) was calculated using the trapezoidal method. 237 Prism (GraphPad software, USA) was used to analyze the data. Differences by treatment were 238 identified using a two-way ANOVA with repeated measures. Post hoc analysis was subjected to 239 Bonferroni correction. $\mathrm{P}$ values less than 0.05 were treated as significant.

$241 \quad$ RESULTS

242 Baseline measurements

243 All baseline measurements of the subjects were within the normal range (Table 2) including blood 244 pressure and FMD. All treatments were well tolerated, with only one participant withdrawing due to an adverse event (gastrointestinal discomfort on both high fibre interventions).

\section{Release of free FA from flatbreads}

248 The levels of free, conjugated and bound FA in the white and high fibre flatbreads are presented in 249 Table 1. Enzyme treatment of high fibre bread resulted in the release of more than $60 \%$ of bound 250 FA, with $30 \mathrm{~g}$ of enzyme-treated high fibre flatbread providing $4.74 \mathrm{mg}$ of free FA, compared to $2510.78 \mathrm{mg}$ in standard high fibre and $0.16 \mathrm{mg}$ in white bread. Three flatbreads were provided per 252 treatment, delivering a $22.21 \mathrm{mg}$ of total FA after consumption of the enzyme-treated high fibre 253 flatbread, compared to $18.87 \mathrm{mg}$ from the non-enzyme treated high fibre flatbread and $1.38 \mathrm{mg}$ from 254 the white flatbread control. 


\section{Vascular function}

257 A time-dependent increase in FMD was observed following consumption of the enzyme-treated 258 high fibre bread with significantly increased brachial arterial dilation at $2 \mathrm{~h}(p<0.05), 5 \mathrm{~h}(p<0.01)$ 259 and $7 \mathrm{~h}(p<0.05)$, relative to the white bread and at $5 \mathrm{~h}(p<0.01)$, relative to non-treated high fibre 260 control $(\mathrm{n}=19)($ Figure 2$)$. FMD increased by $0.9 \pm 0.5 \%$ at $2 \mathrm{~h}, 1.5 \pm 1.1 \%$ at $5 \mathrm{~h}$ and $1.2 \pm 0.9 \%$ 261 at $7 \mathrm{~h}$ for the enzyme-treated high fibre flatbread, relative to baseline. No significant differences in 262 FMD were observed at baseline between groups $(p>0.05)$ or following intake of either the white 263 bread or the non-treated high fibre bread, relative to baseline ( $p>0.05)$, although FMD levels were 264 elevated following consumption of non-treated high fibre flatbread at $7 \mathrm{~h}(\mathrm{p}=0.098, \mathrm{n}=19)$. 265 Blood pressure, heart rate, DVP-SI and DVP-RI were not significantly altered following the 266 consumption of any of the breads (Table 2) or between baseline and post intervention ( $>>0.05 ; 2$ way ANOVA with Bonferroni post-hoc analysis). Following consumption of the enzyme-treated high fibre bread, there was a rise in endothelium-dependent vasodilation (as indicated by increases in skin erythrocyte flux in the presence of acetylcholine chloride) at $5 \mathrm{~h}$ and a return to baseline at $7 \mathrm{~h}$

(Figure 3 (A)), although this was not statistically significantly. Similarly, no changes were observed in response to SNP (endothelium independent) for any of the treatments (Figure 3 (B)).

\section{Plasma ferulic acid analysis}

274 No significant increases in total plasma phenolic acids were observed over the $7 \mathrm{~h}$ period (Figure 275 4(A)). However, a significant increase in plasma ferulic acid was observed following intake of the 276 enzyme-treated high fibre flatbread at $2 \mathrm{~h}(p<0.001)$ and $5 \mathrm{~h}(p<0.01)$, verses white bread and at $2 \mathrm{~h}$ $277(p<0.001)$ and $5 \mathrm{~h}(p<0.05)$, versus non-treated high fibre control (Figure 4 (B)). None of the other 278 individual phenolic acids measured in the study differed between treatments $(\mathrm{p}<0.05$;

\section{Supplementary Figure S2).}




\section{DISCUSSION}

282 In the present study, we show improved acute vascular function following the consumption of the 283 high fibre flatbread which had been treated with an esterase enzyme to release FA bound to 284 arabinoxylan fibre. The release of FA during bread making resulted in a significantly higher level 285 of ferulic acid reaching the circulation (relative to control breads) and resulted in a significant increase in FMD at $2(p<0.05)$ and $5 \mathrm{~h}(p<0.01)$ compared to both the high fibre and white flatbread controls (Figure 2). These results are in agreement with a study which showed that intake of wine containing a similar amount of phenolic acids improves endothelial-independent vasodilation acutely in healthy volunteers [33]. Furthermore, with respect to FMD effect size, our data are also in agreement with previous data sets showing increases in brachial artery dilation at 1-2 and $6 \mathrm{~h}$ following ingestion of, for example the equivalent of $240 \mathrm{~g}$ fresh weight of blueberries (containing 766-1791 mg of polyphenols) [34], cocoa [35, 36], red wine [37] and decaffeinated coffee [38].

The increase in FMD observed in response to the enzyme-treated high fibre flatbread was paralleled by an increase in plasma FA. Previous studies have reported free FA concentrations in plasma of between 150-210 $\mathrm{nM}$ at 1 to 3 hours post consumption of a high bran cereal [39] and $640 \mu \mathrm{mol} / \mathrm{min} / \mathrm{L}$ after consumption of bread [40], with these foods delivering phenolics primarily in the bound-form with no attempt to release FA prior to consumption. There is evidence that FA can be released from arabinoxylan via the action of microbiota-derived esterases and xylanases [21,4143], although this appears to be of limited efficiency, with only about $25 \%$ released by fecal esterases $[21,44,45]$. Previous work has also shown that processing (fermentation and enzyme treatment) of wheat bran can increase free FA in bread by up to 8-fold [46] and lead to increased release of FA in the colon, and consequently increases in derived metabolites such as 3,4dihydroxyphenylpropionic acid, 3-hydroxyphenylpropionic acid and 3-phenylpropionic acid. Such bioprocessed bread has been shown to increase the bioavailability of phenolic acids and lead to subsequent immunomodulatory effects in humans [40]. 
308 With respect to mechanism of action, there are very few studies regarding the physiological actions 309 of FA and its metabolites on endothelial function. Animal studies indicate the potential for FA to 310 improve endothelium dysfunction in aortas of rats with spontaneous hypersensitivity [47], and in 311 conjunction with astragaloside IV in streptozotocin-induced diabetic rats [48]. Both studies 312 concluded that FA increased NO bioavailability via a decrease in NADPH-dependent superoxide 313 anion levels [47] and by regulating eNOS activity [48]. In humans, the intake of oats, which is also 314 rich in FA and other phenolics, has been shown to enhance the FMD response in overweight, 315 dyslipidemic adults, particularly in post-menopausal women [49], providing further support for an 316 NO-mediated mechanism. In addition to such a pathway of activity, it has also been suggested that 317 the intake of any cereal food rich in aleurone cells (which have high contents of fibre, phenolics and 318 other potentially beneficial components) may also improve markers of immune function status, such 319 as C-reactive protein and adhesion molecules [50]. Additional support for the causal activity of 320 phenolic acids in vascular benefits, comes from the late improvement in FMD following 321 consumption of the untreated high fibre bread, in the current study, where the excretion of total 322 phenolic acids was highest. Such metabolites include isoferulic acid, hippuric acid and protocatechuic acid, metabolites known to be products of hydroxycinnamic acids, after bacterial metabolism in the large intestine [51-53]. Similarly, small phenolic metabolites derived from anthocyanin and chlorogenic acid were proposed to mediate improvements in FMD at $6 \mathrm{~h}$ postconsumption of blueberry flavonoids [33].

Another potential mechanism may involve an increase in steady-state NO levels, via inhibition of NADPH oxidase. Ferulic acid may inhibit NADPH oxidase, in a similar manner to the structurally related drug apocynin, thus reducing superoxide levels. This reduction in superoxide formation may maintain nitric oxide levels by limiting the reaction of nitric oxide with superoxide (to form peroxynitrite) and consequently sparing nitric oxide bioavailability to the vasculature. Inhibition of 
333 NADPH oxidase activity by phenolic metabolites, such as FA and isoferulic acid, has been

334 observed in clinical trials following intake of blueberry polyphenols, which occurred concurrently

335 with an increase in FMD [33] and has been noted in cell studies with flavanols [54,55]. FA, and its

336 metabolites, have structural homology to apocynin, a known NADPH oxidase inhibitor [56], with

337 ferulic, vanillic, homovanillic, and hippuric acids, as well as tyrosol and hydroxytyrosol, all

338 possessing significant inhibitory activity $[55,56]$. Further investigation is required to define the

339 detailed mechanism by which wholegrain phenolics exert their activity in humans, however, it

340 appears likely that the interactions of these small phenolics with the endothelium and its local

341 environment may underpin such physiological events.

342 In conclusion, this study has shown that enzymatic processing of high fibre bread can increase the

343 bioavailability of FA and lead to improvements in human vascular function. Our data also suggest

344 that the global influence of wholegrain intake on human cardiovascular health may also relate to the

345 combined influence of both fibre and phenolic acids present within the wholegrain. Further

346 development of innovative baking and bread processing techniques, such as enzymatic treatment of

347 dough to release potential bioactives, may represent a promising approach to improve the bio-

348 accessibility of these beneficial components of wholegrain in a cost-effective way to a wide section

349 of the population.

ACKNOWLEDGEMENTS

352 Rothamsted Research receives grant-aided support from the Biotechnology and Biological Sciences 353 Research Council (BBSRC) of the UK and the work reported here forms part of the Designing 354 Future Wheat Institute Strategic Programme (AL and PRS) [BB/P016855/1] and LVM Tailoring 355 Plant Metabolism [BBS/E/C/000I0420].

356 Conflict of Interest (COI) Statement

357 The authors have declared no conflict of interest. 


\section{Authors' Contributions}

360 Study design (PRS, JPES), phenolic analysis (AA), human study implementation (AA), solid phase 361 extraction (AA), mass spectrometry (LVM, AL), statistical analysis (AA, JPES), data interpretation 362 (AA, AL, PRS, JPES), manuscript preparation (AA, AL, PRS, JPES), manuscript approval (AA, 363 LVM, AL, PRS, JPES). 


\section{REFERENCES}

[1] Vauzour D, Rodriguez-Mateos A, Corona G, Oruna-Concha MJ, Spencer JP. Polyphenols and human health: prevention of disease and mechanisms of action. Nutrients 2010; 2: 1106-31.

[2] Widmer RJ, Flammer AJ, Lerman LO, Lerman A. The Mediterranean diet, its components, and cardiovascular disease. American Journal of Medicine 2015; 128: 229-38.

[3] Tresserra-Rimbau A, Rimm EB, Medina-Remon A, Martinez-Gonzalez MA, de la Torre R, Corella D, et al. Inverse association between habitual polyphenol intake and incidence of cardiovascular events in the PREDIMED study. Nutrition Metabolism and Cardiovascular Diseases. 2014; 24: 639-47.

[4] Khan, N.; Khymenets, O.; Urpí-Sardà, M.; Tulipani, S.; Garcia-Aloy, M.; Monagas, M.; MoraCubillos, X.; Llorach, R.; Andres-Lacueva, C. Cocoa Polyphenols and Inflammatory Markers of Cardiovascular Disease. Nutrients 2014; 6: 844-880.

[5] Wang, L., Yao, Y., He, Z., Wang, D., Liu, A., Zhang, Y. Determination of phenolic acid concentrations in wheat flours produced at different extraction rates. Journal of Cereal Science 2013; 57: 67-72.

[6] Li L, Shewry PR, Ward JL. Phenolic Acids in Wheat Varieties in the HEALTHGRAIN Diversity Screen. Journal of Agricultural and Food Chemistry 2008; 56: 9732-9739.

[7] Borneo R, Leon AE. Whole grain cereals: functional components and health benefits. Food and Function 2012; 3: 110-9.

[8] Belobrajdic DP, Bird AR. The potential role of phytochemicals in wholegrain cereals for the prevention of type-2 diabetes. Nutrition Journal 2013; 12: 62.

[9] Jonnalagadda SS, Harnack L, Liu RH, McKeown N, Seal C, Liu S, Fahey GC. Putting the whole grain puzzle together: health benefits associated with whole grains--summary of American Society for Nutrition 2010 Satellite Symposium. Journal of Nutrition 2011; 141: 1011S-22S.

[10] Mellen, PB, Walsh, TF \& Herrington, DM. Whole grain intake and cardiovascular disease: a meta-analysis. Nutrition Metabolism and Cardiovascular Disease 2008; 18: 283-290.

[11] Aune, D., Keum, N., Giovannucci, E., Fadnes, L.T., Paolo Boffetta, P., Greenwood, D.C., Tonstad, S., Vatten, L.J., Riboli, E., Norat, T. Whole grain consumption and risk of cardiovascular disease, cancer, and all cause and cause specific mortality: systematic review and dose-response meta-analysis of prospective studies. British Medical Journal 2016; 353: i2716.

[12] Qing Ye, E, Chacko, SA, Chou, E.L., Kugizaki, M., Liu, S. Greater whole-grain intake is associated with lower risk of Type 2 diabetes, cardiovascular disease, and weight gain. Journal of Nutrition. 2012; 142: 1304-1313.

[13] Scientific Advisory Committee on Nutrition (2014) Draft SACN Carbohydrates and Health Report. https://www.gov.uk/government/consultations/consultation-on-draft-sacncarbohydrates-and-health-report.

[14] Wei, H., Gao, Z., Liang, R., Li, Z., Hao, H., Liu, X. Whole-grain consumption and the risk of all-cause, CVD and cancer mortality: a meta-analysis of prospective cohort studies British Journal of Nutrition. 2016; 116: 514-525.

[15] Qi L, Meigs JB, Liu S, Manson JE, Mantzoros C, Hu FB. Dietary fibers and glycemic load, obesity, and plasma adiponectin levels in women with type 2 diabetes. Diabetes Care 2006; 29: $1501-5$.

[16] Buscemi S, Verga S, Batsis JA, Tranchina MR, Belmonte S, Mattina A, Re A, Rizzo R, Cerasola G. Dose-dependent effects of decaffeinated coffee on endothelial function in healthy subjects. European Journal of Clinical Nutrition 2009; 63: 1200-1205. 
[17] Bach Knudsen K.E., Nørskov,N.P., Bolvig,A.K., Hedemann, M.S., Nygaard Lærke, H. Dietary fibre and associated phytochemicals in cereals. Molecular and Nutritional Food Research 2017; 61: 7.

[18] Reboredo-Rodríguez, P., Varela-López, A., Forbes-Hernández, T.Y., Gasparrini, M., Sadia Afrin, S., Cianciosi, D., Zhang, J., Piera Pia Manna, P., Bompadre, S., Quiles, J.L., Battino, M., Giampieri, F. Phenolic Compounds Isolated from Olive Oil as Nutraceutical Tools for the Prevention and Management of Cancer and Cardiovascular Diseases. International Journal of Molecular Sciences. 2018; 19: 2305.

[19] Adom KK, Liu RH. Antioxidant Activity of Grains. Journal of Agricultural and Food Chemistry 2002; 50: 6182-6187.

[20] Stone B, Morell M K Carbohydrates, in Khan K and Shewry P R, Wheat: Chemistry and Technology, $4^{\text {th }}$ ed, 2009 St Paul, MN, AACC, 299-362.

[21] Andreasen MF, Kroon PA, Williamson G, Garcia-Conesa M-T. Esterase activity able to hydrolyze dietary antioxidant hydroxycinnamates is distributed along the intestine of mammals. Journal of Agricultural and Food Chemistry 2001a; 49: 5679-5684.

[22] Crozier, A.; Jaganath, I. B.; Clifford, M. N. Dietary phenolics: Chemistry, bioavailability and effects on health. Natural Products Report. 2009; 26: 1001-1043.

[23] Faulds, C.B. What can feruloyl esterases do for us? Phytochemical Review 2010; 9: 121132.

[24] Vollmer, M., Esders, S., Farquharson, F.M., Neugart, S., Duncan, S.H., Schreiner, M., Louis, P., Maul, R., Rohn. S. Mutual Interaction of Phenolic Compounds and Microbiota: Metabolism of Complex Phenolic Apigenin-C- and Kaempferol-O-Derivatives by Human Fecal Samples. Journal of Agricultural and Food Chemistry 2018; 66:485-497.

[25] Vitaglione P, Napolitano A, Fogliano V. Cereal dietary fibre: a natural functional ingredient to deliver phenolic compounds into the gut. Trends in Food Science \& Technology 2008; 19 : 451-463.

[26] Morris SJ, Shore AC. Skin blood flow responses to the iontophoresis of acetylcholine and sodium nitroprusside in man: possible mechanisms. The Journal of Physiology 1996; 496: 531-542.

[27] Ferrell WR, Ramsay JE, Brooks N, Lockhart JC, Dickson S, McNeece GM, Greer IA. Sattar N. Elimination of Electrically Induced Iontophoretic Artefacts: Implications for NonInvasive Assessment of Peripheral Microvascular Function. Journal of Vascular Research 2002; 39: 447-455.

[28] Ramsay JE, Ferrell WR, Greer IA, Sattar N. Factors critical to iontophoretic assessment of vascular reactivity: implications for clinical studies of endothelial dysfunction. Journal of Cardiovascular Pharmacology 2002; 39: 9-17.

[29] Wykretowicz A, Gerstenberger P, Guzik P, Milewska A, Krauze T, Adamska K, Rutkowska A, Wysocki H. Arterial stiffness in relation to subclinical atherosclerosis. European Journal of Clinical Investigation 2009; 39: 11-16.

[30] Millasseau SC, Kelly RP, Ritter JM, Chowienczyk PJ. The vascular impact of aging and vasoactive drugs: comparison of two digital volume pulse measurements. American Journal of Hypertension 2003; 16: 467-472.

[31] de Ferrars, R. M., Czank, C., Saha, S., Needs, P. W., Zhang, Q., Raheem, K. S., Kroon, P. A., Kay, C. D., Methods for isolating, identifying and quantifying anthocyanin metabolites in clinical samples. Analytical Chemistry 2014; 86: 10052-10058.

[32] Norskov, N.P., Hedemann, M.S., Theil, P. K., Fomsgaard, I.S., Laursen, B.B., \& Bach Knudsen, K.E. Phenolic Acids from Wheat Show Different Absorption Profiles in Plasma: A Model Experiment with Catheterized Pigs. Journal of Agriculture and Food Chemistry. 2013; 61: 8842-8850.

[33] Vauzour DEJH, George TW, Corona G, Garnotel R, Jackson KG, Sellier C, Gillery P, Kennedy OB, Lovegrove JA, Spencer JPE. Moderate Champagne consumption promotes an 
acute improvement in acute endothelial-independent vascular function in healthy human volunteers. British Journal of Nutrition 2010; 103: 1168-1178.

[34] Rodriguez-Mateos A, Rendeiro C, Bergillos-Meca T, Tabatabaee S, George TW, Heiss C, Spencer JP. Intake and time dependence of blueberry flavonoid-induced improvements in vascular function: a randomized, controlled, double-blind, crossover intervention study with mechanistic insights into biological activity. The American Journal of Clinical Nutrition 2013; 98: 1179-1191.

[35] Heiss C, Kleinbongard P, Dejam A, Perré S, Schroeter H, Sies H, Kelm M. Acute Consumption of Flavanol-Rich Cocoa and the Reversal of Endothelial Dysfunction in Smokers. Journal of the American College of Cardiology 2005; 46: 1276-1283.

[36] Shrime MG, Bauer SR, McDonald AC, Chowdhury NH, Coltart CE, Ding EL. Flavonoidrich cocoa consumption affects multiple cardiovascular risk factors in a meta-analysis of shortterm studies. The Journal of Nutrition 2011; 141: 1982-1988.

[37] van Bussel BCT, Henry RMA, Schalkwijk CG, Dekker JM, Nijpels G, Feskens EJM, Stehouwer CDA. Alcohol and red wine consumption, but not fruit, vegetables, fish or dairy products, are associated with less endothelial dysfunction and less low-grade inflammation: the Hoorn Study. European Journal of Nutrition. 2018; 57: 1409-1419.

[38] Buscemi, S., Verga, S., Batsis, J. A., Tranchina, M. R., Belmonte, S., Mattina, A., Re, A., Rizzo, R. \& Cerasola, G.. Dose-dependent effects of decaffeinated coffee on endothelial function in healthy subjects. European Journal of Clinical Nutrition. 2009;63:1200-1205.

[39] Kern SM, Bennett RN, Mellon FA, Kroon PA, Garcia-Conesa M-T. Absorption of Hydroxycinnamates in Humans after High-Bran Cereal Consumption. Journal of Agricultural and Food Chemistry 2003; 51: 6050-6055.

[40] Mateo Anson N, Aura AM, Selinheimo E, Mattila I, Poutanen K, Van Den Berg R, Havenaar R, Bast A, Haenen GRMM. Bioprocessing of wheat bran in whole wheat bread increases the bioavailability of phenolic acids in men and exerts anti-inflammatory effects ex vivo. The Journal of Nutrition 2011; 141: 137-143.

[41] Kroon PA, Faulds CB, Ryden P, Robertson JA, Williamson G. Release of Covalently Bound FA from Fiber in the Human Colon. Journal of Agricultural and Food Chemistry 1997; 45: 661-667.

[42] Andreasen MF, Kroon PA, Williamson G, Garcia-Conesa M-T. Intestinal release and uptake of phenolic antioxidant diFAs. Free Radical Biology and Medicine 2001b; 31: 304-314.

[43] Buchanan CJ, Wallace G, Fry SC, Eastwood MA. In vivo release of ${ }^{14} \mathrm{C}$-labelled phenolic groups from intact dietary spinach cell walls during passage through the rat intestine. Journal of the Science of Food and Agriculture 1996; 71: 459-469.

[44] Stalmach, A., Steiling, H., Williamson, G., Crozier, A. 2010. Bioavailability of chlorogenic acids following acute ingestion of coffee by humans with an ileostomy. Arch. Biochem. Biophys. 501; 1: 98-105.

[45] Williamson, G., Clifford, M.N. 2017. Role of the small intestine, colon and microbiota in determining the metabolic fate of polyphenols. Biochemical Pharmacology 139:24-39.

[46] Anson NM, Selinheimo E, Havenaar R, Aura A-M, Mattila I, Lehtinen P, Bast A, Poutanen $\mathrm{K}$, Haenen GRMM. Bioprocessing of wheat bran Improves in vitro bioaccessibility and colonic metabolism of phenolic compounds. Journal of Agricultural and Food Chemistry 2009; 57: 6148-6155.

[47] Suzuki A, Yamamoto M, Jokura H, Fujii A, Tokimitsu I, Hase T, Saito I. FA restores endothelium-dependent vasodilation in aortas of spontaneously hypertensive rats. American Journal of Hypertension 2007; 20: 508-513.

[48] Yin Y, Qi F, Song Z, Zhang B, Teng J. FA combined with astragaloside IV protects against vascular endothelial dysfunction in diabetic rats. Bioscience Trends 2014; 8: 217-226.

[49] Katz DL, Evans MA, Chan W, Nawaz H, Comerford BP, Hoxley ML, Njike VY, Sarrel PM. Oats, antioxidants and endothelial function in overweight, dyslipidemic adults. Journal of the American College of Nutrition 2004; 23: 397-403. 
[50] Price RK, Wallace JM, Hamill LL, Keaveney EM, Strain J, Parker MJ, Welch RW. Evaluation of the effect of wheat aleurone-rich foods on markers of antioxidant status, inflammation and endothelial function in apparently healthy men and women. British Journal of Nutrition 2012; 108: 1644-1651.

[51] Rechner AR, Spencer JP, Kuhnle G, Hahn U, Rice-Evans CA. Novel biomarkers of the metabolism of caffeic acid derivatives in vivo. Free Radical Biology and Medicine 2001; 30: 1213-1222.

[52] Caccetta RA-A, Croft KD, Beilin LJ, Puddey IB. Ingestion of red wine significantly increases plasma phenolic acid concentrations but does not acutely affect ex vivo lipoprotein oxidizability. The American Journal of Clinical Nutrition 2000; 71: 67-74.

[53] Choudhury R, Srai SK, Debnam E, Rice-Evans CA. Urinary excretion of hydroxycinnamates and flavonoids after oral and intravenous administration. Free Radical Biology and Medicine 1999; 27: 278-286.

[54] Steffen Y, Gruber C, Schewe T, Sies H. Mono-O-methylated flavanols and other flavonoids as inhibitors of endothelial NADPH oxidase. Archives of Biochemistry and Biophysics 2008; 469: 209-219.

[55] Steffen Y, Schewe T, Sies H. (-)-Epicatechin elevates nitric oxide in endothelial cells via inhibition of NADPH oxidase. Biochemical and Biophysical Research Communications 2007; 359: 828-833.

[56] Stolk J, Hiltermann T, Dijkman J, Verhoeven A. Characteristics of the inhibition of NADPH oxidase activation in neutrophils by apocynin, a methoxy-substituted catechol. American Journal of Respiratory Cell and Molecular Biology 1994; 11: 95-102. 
Table 1.

Baseline fasting characteristics of study population. ${ }^{1}$

\begin{tabular}{ll}
\hline Characteristic & Value \\
\hline Age $(\mathrm{yrs})$ & $26.6 \pm 6.4$ \\
Height $(\mathrm{m})$ & $1.8 \pm 0.1$ \\
Weight $(\mathrm{kg})$ & $76.6 \pm 11.7$ \\
BMI $\left(\mathrm{kg} / \mathrm{m}^{2}\right.$ & $24.2 \pm 2.4$ \\
Waist circumference $(\mathrm{cm})$ & $81.9 \pm 5.7$ \\
BP $(\mathrm{mmHg})$ & \\
$\quad$ Systolic & $121.2 \pm 10.8$ \\
$\quad$ Diastolic & $70.3 \pm 8.0$ \\
Total cholesterol (mmol/l) & $4.4 \pm 0.8$ \\
Glucose (mmol/l) & $5.3 \pm 0.4$ \\
TAG (mmol/l) & $0.8 \pm 0.3$ \\
Brachial artery diameter $(\mathrm{mm})$ & $4.1 \pm 0.5$ \\
FMD \% & $4.8 \pm 1.6$
\end{tabular}

${ }^{1}$ Values are means \pm SD. $(n=19)$. 
Table 2.

Compositional analysis of white, non-treated high fibre and enzyme-treated high fibre flatbreads. ${ }^{1}$

Composition

\begin{tabular}{|c|c|c|c|}
\hline \multirow[b]{2}{*}{ Compounds } & \multicolumn{3}{|c|}{ Composition } \\
\hline & White & $\begin{array}{c}\text { Non-Treated } \\
\text { High Fibre }\end{array}$ & $\begin{array}{c}\text { Enzyme-treated } \\
\text { High Fibre }\end{array}$ \\
\hline White flour (\%) & 60.5 & 0.0 & 0 \\
\hline High Fibre flour (\%) & 0.0 & 60.5 & 60.5 \\
\hline Water $(\%)$ & 34.8 & 34.8 & 34.8 \\
\hline Ultraflo L $®$ activated (\%) & 0.0 & 0.0 & 3.9 \\
\hline Ultraflo L $®$ de-activated (\%) & 3.9 & 3.9 & 0 \\
\hline Salt $(\%)$ & 0.8 & 0.8 & 0.8 \\
\hline Energy (k joules) $(\mathrm{kj} / 100 \mathrm{~g})$ & 1169.0 & 1193.0 & 1247.0 \\
\hline Energy (k calories) (kcal/100g) & 276.0 & 282.0 & 294.0 \\
\hline Protein $(g / 100 g)$ & 7.70 & 8.90 & 9.20 \\
\hline Total Carbohydrate (g/100g) & 60.60 & 61.10 & 63.00 \\
\hline Total sugars (g/100g) & 3.30 & 4.00 & 3.70 \\
\hline Fat $(g / 100 g)$ & 0.80 & 1.20 & 1.30 \\
\hline Saturates $(g / 100 g)$ & 0.14 & 0.24 & 0.26 \\
\hline Monounsaturates (g/100g) & 1.23 & 0.24 & 0.18 \\
\hline Polyunsaturates (g/100g) & 0.39 & 0.67 & 0.80 \\
\hline Trans fatty acids (g/100g) & $<0.1$ & $<0.1$ & $<0.1$ \\
\hline Total fibre $(\mathrm{g} / 100 \mathrm{~g})$ & 2.40 & 4.60 & 3.20 \\
\hline Sodium (mg/100g) & 315.00 & 320.00 & 315.00 \\
\hline Moisture content (g/100g) & 29.70 & 27.30 & 25.00 \\
\hline Ash content (g/100g) & 1.18 & 1.48 & 1.54 \\
\hline Free FA (mg/100g) & 0.53 & 2.60 & 15.80 \\
\hline Conjugated FA (mg/100g) & 0.01 & 1.47 & 0.33 \\
\hline Bound FA (mg/100g) & 1.00 & 16.90 & 9.43 \\
\hline Total FA (mg/100g) & 1.54 & 20.97 & 25.56 \\
\hline
\end{tabular}

${ }^{1}$ Values based on freeze dried flatbread. 
Table 3. Acute effects of interventions on blood pressure, heart rate and DVP. ${ }^{1}$

\begin{tabular}{|c|c|c|c|c|}
\hline & Baseline & $2 \mathrm{~h}$ & $5 \mathrm{~h}$ & $7 \mathrm{~h}$ \\
\hline \multicolumn{5}{|l|}{ Systolic blood pressure } \\
\hline \multicolumn{5}{|l|}{ (mm Hg) } \\
\hline White & $124 \pm 2$ & $121 \pm 2$ & $120 \pm 3$ & $121 \pm 2$ \\
\hline Non-Treated High Fibre & $121 \pm 2$ & $120 \pm 2$ & $120 \pm 2$ & $121 \pm 2$ \\
\hline Enzyme-Treated High Fibre & $121 \pm 2$ & $121 \pm 2$ & $120 \pm 2$ & $120 \pm 2$ \\
\hline \multicolumn{5}{|l|}{ Diastolic blood pressure } \\
\hline \multicolumn{5}{|l|}{ (mm Hg) } \\
\hline White & $71 \pm 1$ & $68 \pm 1$ & $67 \pm 1$ & $72 \pm 2$ \\
\hline Non-Treated High Fibre & $73 \pm 2$ & $68 \pm 1$ & $68 \pm 2$ & $71 \pm 2$ \\
\hline Enzyme-Treated High Fibre & $71 \pm 1$ & $69 \pm 1$ & $67 \pm 1$ & $71 \pm 1$ \\
\hline \multicolumn{5}{|l|}{ Heart rate (beats/min) } \\
\hline White & $56 \pm 2$ & $58 \pm 2$ & $59 \pm 2$ & $57 \pm 2$ \\
\hline Non-Treated High Fibre & $59 \pm 2$ & $60 \pm 2$ & $62 \pm 2$ & $59 \pm 2$ \\
\hline Enzyme-Treated High Fibre & $59 \pm 2$ & $61 \pm 2$ & $60 \pm 2$ & $60 \pm 2$ \\
\hline \multicolumn{5}{|l|}{ DVP-SI (m/s) } \\
\hline White & $5.14 \pm .8$ & $5.3 \pm 1$ & $5.2 \pm 1$ & $5.6 \pm 0.4$ \\
\hline Non-Treated High Fibre & $5.2 \pm 0.3$ & $5.5 \pm 0.4$ & $5.5 \pm 0.4$ & $5.4 \pm 0.5$ \\
\hline Enzyme-Treated High Fibre & $5.5 \pm 0.3$ & $5.4 \pm 0.4$ & $5.5 \pm 0.4$ & $5.4 \pm 0.4$ \\
\hline \multicolumn{5}{|l|}{ DVP-RI (\%) } \\
\hline White & $67 \pm 12$ & $66.6 \pm 13$ & $60.7 \pm 13$ & $62.1 \pm 10$ \\
\hline Non-Treated High Fibre & $64.2 \pm 15$ & $63.9 \pm 10$ & $60.5 \pm 11$ & $60.5 \pm 7$ \\
\hline Enzyme-Treated High Fibre & $66.2 \pm 12$ & $62.7 \pm 14$ & $62.1 \pm 14$ & $61 \pm 12$ \\
\hline
\end{tabular}

${ }^{1}$ Values are means \pm SEM. $(n=19)$. 


\section{Figure Legends.}

Figure 1. Consort Diagram. Flow diagram of the progress through the phases of the randomised clinical trial indicating participant numbers at enrolment, intervention allocation, follow-up, and data analysis.

Figure 2. Time dependent changes in FMD $(n=19$, mean \pm SD) following consumption of enzymetreated high fibre $(\boldsymbol{\Delta})$, non-treated high fibre $(\boldsymbol{\square})$ and white bread $(\bullet)$. Data were analyzed using 2way ANOVA with post-hoc analysis conducted by using a Bonferroni multiple-comparisons test. Levels of significance between samples are indicated as follows: enzyme-treated high fibre flatbread verses white flatbread; $2 \mathrm{~h}(* \mathrm{p}<0.05), 5 \mathrm{~h}(* * \mathrm{p}<0.01)$ and $7 \mathrm{~h}(* \mathrm{p}<0.05)$ and enzymetreated high fibre flatbread vs non-treated high fibre flatbread $5 \mathrm{~h}(\mathrm{~b}: \mathrm{p}<0.01)$.

Figure 3. Response of forearm skin erythrocyte flux following the iontophoresis of (A) acetylcholine chloride and (B) sodium nitroprusside $(\mathrm{n}=19)$ after consumption of white $(\bullet)$, nontreated high fibre (ם) and enzyme-treated high fibre $(\boldsymbol{\Delta})$ flatbread. Values are means \pm SEM.

Figure 4. (A). Total phenolic acids, in plasma at baseline, 2, 5 and $7 \mathrm{~h}$ following consumption of white $(\bullet)$, non-treated high fibre $(\boldsymbol{\square})$ and enzyme-treated high fibre $(\boldsymbol{\Delta})$ flatbread (n=18; mean \pm SEM). (B). Concentration of free FA in plasma at baseline, 2, 5 and $7 \mathrm{~h}$ following consumption of white $(\bullet)$, non-treated high fibre $(\boldsymbol{\square})$ and enzyme-treated high fibre $(\boldsymbol{\Delta})$ flatbread (n=18; mean \pm SEM). Data were measured using 2-factor repeated measures ANOVA with time and treatment as the 2 factors. Post hoc analysis was conducted using a Bonferroni multiple comparisons test. a: white vs enzyme-treated high fibre, $\mathrm{p}<0.001$; $\mathrm{b}$ : white vs enzyme-treated high fibre, $\mathrm{p}<0.01$; $\mathrm{c}$ : nontreated high fibre vs enzyme treated high fibre, $\mathrm{p}<0.001$; $\mathrm{d}$ : non-treated high fibre vs enzymetreated high fibre, $\mathrm{p}<0.5$. 